\title{
UJI ANTIOKSIDAN EKSTRAK AIR DAN EKSTRAK ETANOL DAGING DAN KULIT BUAH BLEWAH
}

\author{
(Cucumis melo L.) \\ Antonius Padua Ratu ${ }^{1 *}$, Herson C. Himawan ${ }^{1}$, M. Rio Radhi ${ }^{1}$ \\ ${ }^{1}$ Program Studi S1 Farmasi Sekolah Tinggi Teknologi Industri dan Farmasi Bogor \\ *Korespodensi:antoniuspaduaratu@gmail.com
}

\begin{abstract}
ABSTRAK
Kandungan sitrulin yang tinggi dapat berkontribusi terhadap oksidatif stress sebagai penangkap radikal bebas (radical scavenger). Tanaman dari keluarga Cucurbitaceae ditemukan sitrulin dalam jumlah yang tinggi.Salah satunya tanaman keluarga Cucurbitaceae adalah blewah (Cucumis melo L.)Tujuan penelitian ini adalah untuk memperoleh aktivitas antioksidan yang paling optimal pada daging dan kulit buah blewah dengan beberapa metode ekstraksi.Metode yang digunakan ialah metode maserasi dengan pelarut etanol dan air, metode digesti dan dekokta hanya dengan pelarut air. Aktivitas antioksidan tertinggi ditunjukkan oleh metode maserasi ekstrak etanol kulit blewah $(583,19 \mathrm{mg} / \mathrm{L})$. Pada ekstrak air, metode maserasi kulit blewah memberikan aktivitas antioksidan $(722,17 \mathrm{mg} / \mathrm{L})$ yang berbeda nyata $(\mathrm{P}<0,05)$ dengan metode digesti dan dekokta pelarut air lainnya. Namun aktivitas antioksidan ektrak daging dan kulit blewah tersebut lebih rendah dibandingkan dengan vitamin $\mathrm{C}$.
\end{abstract}

Kata kunci : antioksidan, Cucumis melo L., dekokta, digesti, ekstraksi, maserasi.

\begin{abstract}
High content of sitrulin can contribute to oxidative stress as a free radical scavenger. Plants from the Cucurbitaceae family are found in high quantities of Citrulline. One of Cucurbitaceae family is cantaloupe (Cucumis melo L.) The purpose of this study was to determine the antioxidant activity which is optimal in the flesh and rind cantaloupe against extraction methods. The method was used maceration with the ethanol and water, methods of digestion and decocta only with water solvent. The high antioxidant activity was shown by ethanol extract cantaloupe was rind maceration method $(583.19 \mathrm{mg} / \mathrm{L})$. In the water extract, rind maceration method of cantaloupe provides antioxidant activity $(722.17 \mathrm{mg} / \mathrm{L})$ were significantly different $(\mathrm{P}<0,05)$ than the water solvent digestion method and decocta method. However, the antioxidant activity of the flesh and rind extract from cantaloupe is lower than vitamin C.
\end{abstract}

Keywords : antioxidant, Cucumis melo L., decocta, digestion, extraction, maceration 


\section{PENDAHULUAN}

Blewah merupakan salah satu tanaman yang tumbuh di negara tropis seperti Indonesia ini.Blewah merupakan buah dari keluarga Cucurbitaceae, termasuk juga semangka, melon, dan labu. Menurut United States Department of Agriculture (USDA) National Nutrient database, blewah mengandung asam amino sebesar 0,8 gram/100 gram [1]. Sitrulin merupakan salah satu asam amino yang berpotensi dalam meningkatkan kesehatan.Kandungan sitrulin yang tinggi dapat berkontribusi terhadap oksidatif stress sebagai penangkap radikal bebas (radical scavenger) [2].Pada tanaman, sitrulin banyak ditemukan dalam jumlah yang tinggi pada beberapa keluarga Cucurbitaceae, khususnya semangka, alga, dan beberapa Grateloupia vulgaris[3].

Berdasarkan penelitian yang dilakukan oleh Silabi (2015) pada Uji Antioksidan Ekstrak Pigmen Karotenoid dan Sitrulin pada Kulit Buah Blewah (Cucumis melo L.) secara In Vitro (Metode DPPH) dengan penggunaan tiga pelarut berbeda yaitu petroleum eter, aseton, dan air menunjukkan bahwa kulit blewah tanpa proses pengeringan yang diekstraksi menggunakan pelarut air memiliki aktivitas antioksidan lemah $(667,30 \mathrm{mg} / \mathrm{L})$ [4].

Berdasarkan hasil pada penelitian tersebut maka akan dilakukan penelitian lanjutan antioksidan dari ekstrak kulit dan ekstrak daging buah blewah tanpa proses pengeringan menggunakan pelarut air dan etanol dengan metode ekstraksi yang berbeda untuk mendapatkan metode paling optimal.

Penelitian ini bertujuan untuk memperoleh aktivitas antioksidan yang optimal pada ekstrak air dan ekstrak etanol dari daging serta kulit buah blewah dengan perbedaan metode ekstraksi.

\section{METODE PENELITIAN}

Peralatan yang digunakan dalam penelitian ini adalah peralatan gelas, penangas air (Digital Thermostat Waterbath H-WBE-8L), spektrofotometer Vis (UV Mini-1240 Shimadzu), rotary evaporator $\left(\mathrm{IKA}^{\circledR} \mathrm{RV} 10\right.$ Basic).

Bahan yang digunakan dalam penelitian ini adalah daging buah blewah, kulit buah blewah, air, etanol 96\%, ammonia $0,05 \mathrm{~N}$ dalam kloroform, $\mathrm{H}_{2} \mathrm{SO}_{4} 2 \mathrm{~N}$, pereaksi Mayer, Wagner dan Dragendorft, pereaksi Shinoda (campuran logam magnesium dan $\mathrm{HCl}$ ), $\mathrm{NaOH} 10 \%$, pereaksi Lieberman-Burchard standar vitamin C dan 2,2-difenil-1-pikrilhidrazil (DPPH).

\section{Persiapan Bahan Baku}

Buah blewah diperoleh dari daerah Solo, Jawa Tengah.Buah blewah tersebut diambil bagian daging dan kulit buahnya. Bagian kulit buah blewah diambil dari bagian bawah hingga kulit terluar (kira-kira $1 \mathrm{~cm}$ ), lalu di potong kecil-kecil daging dan kulit buah blewah dengan ketebalan lebih kurangnya $0,5 \mathrm{~cm}$.

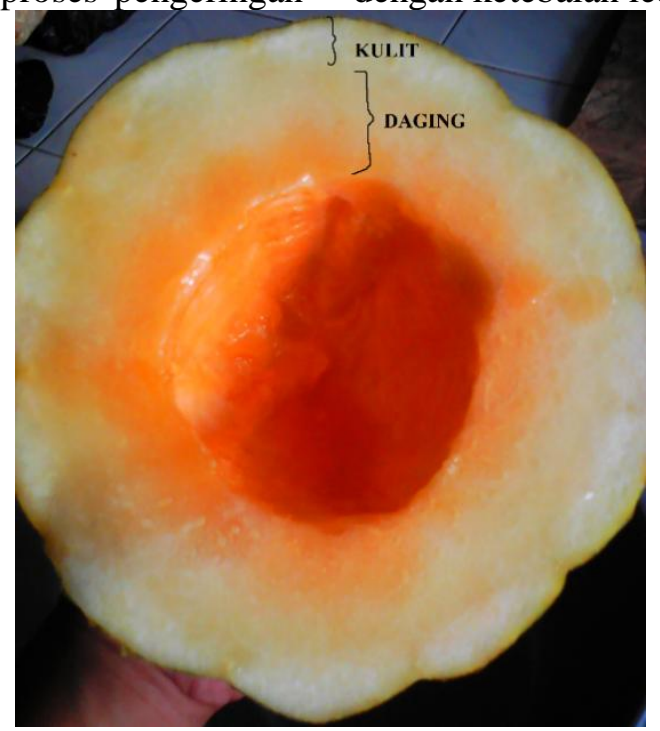

Gambar 1. Posisi Pengambilan Daging dan Kulit Buah Blewah

\section{Ekstraksi Daging dan Kulit Buah}


Ekstraksi daging dan kulit buah blewah dilakukan menggunakan 3 metode ekstraksi yaitu maserasi dengan pelarut air dan etanol $96 \%$, digesti dengan pelarut air, dan dekokta dengan pelarut air.

Setelah ekstraksi selesai dilakukan, filtrat yang didapatkan dilakukan pengentalan dengan rotary vaccum evaporator untuk mendapatkan ekstrak kental dan pekat.

\section{Penapisan Fitokimia}

Pengujian fitokimia pada ekstrak yang diperoleh untuk mengetahui kandungan senyawanya. Pengujian yang dilakukan meliputi uji alkaloid, uji flavonoid, uji saponin, uji terpenoid dan steroid

\section{Uji Aktivitas Antioksidan}

Sampel dilarutkan menggunakan etanol pada konsentrasi 100, 200, 300 dan 400 ppm dan dimasukkan ke dalam tabung reaksi. Sampel yang telah diatur konsentrasinya kemudian ditambahkan 2,2-difenil-1pikrilhidrazil (DPPH) $0.2 \mathrm{mM}$ sebanyak $1 \mathrm{~mL}$ dan didiamkan selama 30 menit. Setelah 30 menit, diukur absorbansinya pada panjang gelombang $517 \mathrm{~nm}$ setelah diukur absorbansi kontrol negatif. Kontrol negatif dibuat dengan cara membuat larutan $4 \mathrm{~mL}$ etanol dengan $1 \mathrm{~mL}$ larutan DPPH $0.2 \mathrm{mM}$. Faktor koreksi dari larutan sampel dibaca absorbansinya sebagai blanko sampel.Aktivitas scavenging terhadap radikal bebas DPPH dinyatakan sebagai persen penghambatan terhadap radikal DPPH. Persen penghambatan dihitung sesuai rumus :

$$
\begin{aligned}
& \text { \%Aktivitas antioksidan } \\
& \qquad=\frac{A k-(A s-A o)}{A k} \times 100 \%
\end{aligned}
$$

Keterangan:

$\mathrm{Ak}=$ Absorbansi kontrol negatif (pelarut etanol + pereaksi DPPH 0,2 mM)

Ao $=$ Absorbansi blanko (etanol)

As = Absorbansi sampel (ekstrak pekat air/etanol (kulit/buah blewah) + pelarut etanol + pereaksi DPPH 0,2 mM)

Persen penghambatan masing-masing konsentrasi sample diplot masing-masing pada sumbu x dan y pada persamaan regresi linear. Persamaan regresi linear yang diperoleh dalam bentuk persamaan $\mathrm{y}=\mathrm{a}+\mathrm{bx}$ digunakan untuk mencari nilai $\mathrm{IC}_{50}$ (inhibitor concentration $50 \%$ ) dari masing-masing sampel dengan menyatakan nilai y sebesar 50 dan nilai x yang akan diperoleh sebagai $\mathrm{IC}_{50}$.

Data aktivitas antioksidan masing-masing hasil ekstraksi yang diperoleh, diolah dengan menggunakan ANOVA satu arah yang diolah menggunakan software SPSS Statistics ver. 13.0 for Windows, yang telah diketahui uji normalitasnya, dengan taraf kepercayaan 95\% sehingga dapat diketahui apakah perbedaan yang diperoleh bermakna atau tidak dengan nilai signifikansi $(\mathrm{p} \leq 0,05)$.

\section{HASIL DAN PEMBAHASAN}

Pembuatan simplisia daging dan kulit buah blewah dilakukan tanpa pengeringan. Didapat masing-masing bobot simplisia segar daging dan kulit buah blewah yaitu 2080 gram. Untuk mendapatkan ekstrak daging dan kulit buah blewah dilakukan ekstraksi dengan 3 metode yang berbeda, yaitu maserasi, digesti, dan dekokta. Maserasi dilakukan dengan cara merendam sampel dalam cairan penyari. Cairan penyari akan menembus dinding sel dan masuk ke dalam rongga sel yang mengandung zat aktif sehingga zat aktif akan larut. Adanya perbedaan konsentrasi antara larutan zat aktif di dalam sel dengan di luar sel, menyebabkan larutan yang pekat di dalam sel didesak keluar.Oleh karena itu dilakukan pula metode ekstraksi dengan pemanasan yaitu digesti dan dekokta untuk mengetahui tingkat optimum kandungan senyawa sitrulin serta aktivitas antioksidan yang diberikan ekstrak daging dan kulit buah blewah. Metode ekstraksi digesti dan dekokta dilakukan dengan cara yang hampir sama dengan maserasi, yaitu dengan cara merendam sampel dalam cairan penyari. Pembedanya adalah pada metode digesti menggunakan temperatur $40-50{ }^{\circ} \mathrm{C}$, sedangkan metode dekokta menggunakan temperatur $90-100$ ${ }^{\circ}$ C.Bobot ekstrak setelah dilakukan pengentalan dapat dilihat pada Tabel 1 .

Tabel 1.Data Bobot Ekstrak Sebelum dan Sesudah Dilakukan Pengentalan 


\begin{tabular}{ccccc}
\hline Simplisia & Metode & Pelarut & $\begin{array}{c}\text { Bobot ekstrak } \\
\text { awal }(\mathbf{g})\end{array}$ & $\begin{array}{c}\text { Bobot ekstrak } \\
\text { akhir }(\mathbf{g})\end{array}$ \\
\hline Kulit Blewah & Maserasi & Etanol 96\% & 520 & 11,63 \\
& Maserasi & Air & 520 & 23,71 \\
\cline { 2 - 5 } & Digesti & Air & 520 & 15,21 \\
\cline { 2 - 5 } & Dekokta & Air & 520 & 23,42 \\
\hline \multirow{2}{*}{ Daging } & Maserasi & Etanol 96\% & 520 & 10,74 \\
& Maserasi & Air & 520 & 10,95 \\
\cline { 2 - 5 } & Digesti & Air & 520 & 14,27 \\
\cline { 2 - 5 } & Dekokta & Air & 520 & 21,45 \\
\hline
\end{tabular}

\section{Uji Fitokimia}

Uji fitokimia ini bertujuan untuk menganalisis bagian tumbuhan sehingga dapat diketahui kandungan bioaktif yang berguna untuk pengobatan.Dalam pengujian ini dihasilkan bahwa uji alkaloid positif pada ekstrak etanol metode maserasi, ekstrak air metode digesti dan dekokta untuk masingmasing simplisia.Pada ekstrak air metode digesti pada kulit dan daging blewah memberikan hasil positif untuk senyawa terpenoid, begitu juga dengan ekstrak air metode dekokta pada daging blewah.

Alkaloid tidak larut dalam air, tetapi dapat terlarut dalam larutan asam dan diekstraksi menggunakan pelarut organik.Meskipun alkaloid terdapat pada tanaman dalam jumlah banyak, tetapi hanya pada satu bagian tertentu yang mengandung alkaloid.Dari data pengamatan di atas didapat alkaloid pada masing-masing simplisia, yaitu metode maserasi dengan pelarut etanol, metode digesti dan dekokta pelarut air.

Tabel 2. Hasil Penapisan Fitokimia Ekstrak Kulit dan Daging Buah Blewah

\begin{tabular}{cccccccc}
\hline Simplisia & Pelarut & Ekstrak & \multicolumn{5}{c}{ Uji Fitokimia } \\
\cline { 3 - 8 } & & & Alkaloid & Flavonoid & Steroid & Terpenoid & Saponin \\
\hline Kulit & Etanol & Maserasi & + & - & - & - & - \\
\cline { 2 - 7 } Buah & Air & Maserasi & - & - & - & - & - \\
Blewah & & Digesti & + & - & - & + & - \\
& & Dekokta & + & - & - & - & - \\
\hline Daging & Etanol & Maserasi & + & - & - & - & - \\
\cline { 2 - 7 } Buah & Air & Maserasi & - & - & - & - & - \\
Blewah & & Digesti & + & - & - & + & - \\
& & Dekokta & + & - & - & + & - \\
\hline
\end{tabular}

Keterangan : (+) mengandung senyawa; (-) tidak mengandung senyawa

Flavonoid merupakan senyawa polifenol yang bersifat sebagai antioksidan alami dan terdapat hampir pada semua sel tanaman.Flavonoid merupakan senyawa polar dan cukup asam. Menurut Sroimori (2011), pada semua bagian kulit blewah mengandung senyawa fenolik $\pm 1,10 \mathrm{mg}$ ekuivalen asam galat/g pada pelarut etanol-air (8:2) [5] Sedangkan dari hasil yang didapat tidak mengandung flavonoid, hal ini bisa dikarenakan metode penarikan senyawa flavonoid pada uji fitokimia tidak begitu kuat.

Terpenoid terdiri dari beberapa macam senyawa seperti monoterpen dan seskuiterpen yang mudah menguap, diterpen yang sukar menguap, dan yang tidak menguap triterpen dan sterol.Secara umum terpen terdapat dalam sitoplasma sel tumbuhan, terpen tidak larut dalam air tetapi larut dalam pelarut organik. Dari data pengamatan di atas, terpenoid terdapat pada simplisia kulit metode digesti pelarut air dan simplisia daging metode digesti dan dekokta pelarut air. Hal ini bisa dikarenakan proses pemanasan menimbulkan aktivitas senyawa terpenoid yang lebih baik.

\section{Aktivitas Antioksidan}

Aktivitas antioksidan dilakukan dengan menggunakan metode pemberian radikal bebas DPPH. Prinsip kerja metode ini adalah adanya 
senyawa antioksidan yang mendonorkan $\mathrm{H}^{+}$pada radikal bebas DPPH sehingga merubah radikal bebas DPPH yang semula berwarna ungu menjadi senyawa non radikal 1,1-difeni-2- pikril-hidrazin berwarna kuning pucat, maka absorpsi akan berkurang menjadi kuning pucat atau warnanya pudar, dapat diukur serapannya pada panjang gelombang $516 \mathrm{~nm}$.

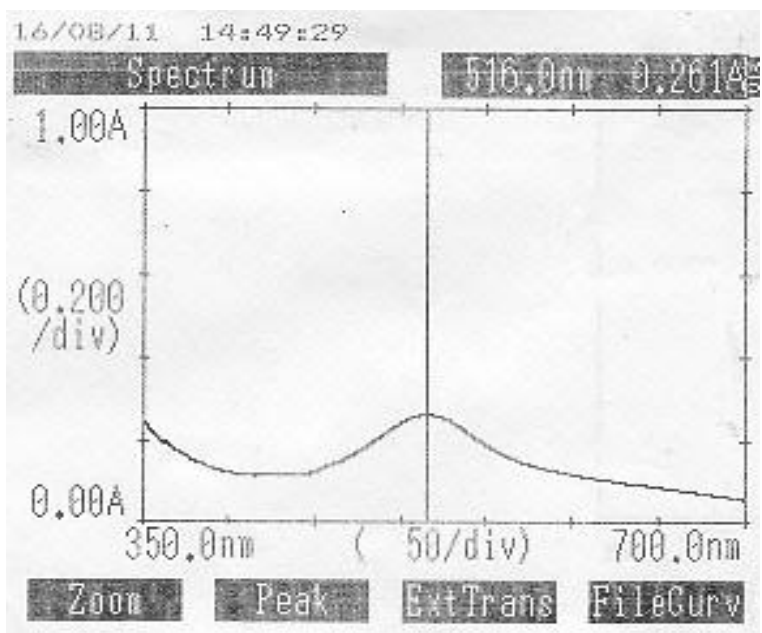

Gambar 2. Kurva Panjang Gelombang Maksimum Larutan DPPH

Aktivitas antioksidan daging dan kulit buah blewah dinyatakan dengan adanya pengurangan nilai absorbansi kontrol DPPH terhadap nilai absorbansi DPPH yang direaksikan dengan sampel larutan uji.Perubahan nilai absorbansi diukur dengan spektrofotometer yang dinyatakan dengan persen penghambatan, lalu diplotkan terhadap konsentrasi. Sehingga akan didapatkan nilai $\mathrm{IC}_{50}$ yang dihitung dengan menggunakan persamaan regresi yang diperoleh dengan memasukkan angka 50 pada persamaan garis $(\mathrm{y}=50)$. Nilai $\mathrm{IC}_{50}$ untuk ekstrak daging dan kulit blewah adalah sebagai berikut.

Tabel 3.IC ${ }_{50}$ Antioksidan Ekstrak Daging dan Kulit Blewah Dengan Pelarut Air dan Etanol

\begin{tabular}{lllr}
\hline \multirow{2}{*}{ Pelarut } & \multicolumn{1}{c}{$\begin{array}{c}\text { Bagian Buah } \\
\text { Blewah }\end{array}$} & Metode Ekstraksi & $\begin{array}{c}\text { IC }_{\mathbf{5 0}} \text { Antioksidan } \\
(\mathbf{m g} / \mathbf{L})\end{array}$ \\
\hline Etanol & Kulit & Maserasi & 583,19 \\
& Daging & Maserasi & 1387,67 \\
\hline Air & Kulit & Maserasi & 722,17 \\
& & Digesti & 1283,75 \\
& & Dekokta & 1247,66 \\
\cline { 2 - 4 } & Daging & Maserasi & 1363,11 \\
& & Digesti & 866,02 \\
& & Dekokta & 777,26 \\
\hline
\end{tabular}

Berdasarkan analisis ragam, pada uji Tukey HSD perlakuan metode maserasi ekstrak air kulit blewah memberikan aktivitas yang paling baik pada kepercayaan 95\% $(\mathrm{P}<0,05)$. Berdasarkan data, aktivitas antioksidan pada metode maserasi ekstrak kulit blewah dengan pelarut air $(722,17 \mathrm{mg} / \mathrm{L})$ lebih baik dibandingan metode dengan pelarut air lainnya. Namun apabila dibandingkan dengan pelarut etanol 96\%, maka metode maserasi ekstrak kulit blewah dengan pelarut etanol masih lebih baik $(583,19 \mathrm{mg} / \mathrm{L})$. Pada penelitian ini didapatkan hasil aktivitas antioksidan lebih baik dibandingkan pada penelitian sebelumnya yang menggunakan metode ekstraksi dengan pelarut air $(667,30 \mathrm{mg} / \mathrm{L})$.

Pada perlakuan daging blewah, metode dekokta ekstrak air $(777,26 \quad \mathrm{mg} / \mathrm{L})$ menunjukkan aktivtias antioksidan yang lebih baik dibandingkan metode maserasi ekstrak 
etanol dan air pada daging blewah, serta metode digesti ekstrak air yang memiliki aktivitas yang rendah $(1387,67 \mathrm{mg} / \mathrm{L} ; 1363,11 \mathrm{mg} / \mathrm{L} ; 866,02$ $\mathrm{mg} / \mathrm{L})$. Hal ini bisa dikarenakan adanya senyawa lain diluar sitrulin ataupun dalam golongan senyawa lain yang bersifat antioksidan dan lebih tahan panas. Hal ini membuktikan bahwa pada kulit buah blewah memiliki aktivitas antioksidan yang lebih optimal dalam menangkal radikal bebas serta memberikan nilai $\mathrm{IC}_{50}$ yang berbeda pula.

Pada penelitian ini dilakukan pengukuran terhadap sampel daging dan kulit blewah digunakan larutan pembanding asam askorbat dengan konsentrasi 100-400 $\mathrm{mg} / \mathrm{L}$ untuk membandingkan kemampuan menangkal radikal bebas.

Aktivitas antioksidan larutan asam askorbat (vitamin C) didapat rata-rata 290,33 $\mathrm{mg} / \mathrm{L}$. Aktivitas antioksidan larutan asam askorbat jauh lebih baik daripada aktivitas antioksidan daging dan kulit buah blewah, oleh karena itu belum sebanding dengan larutan asam askorbat walaupun telah dilakukan berbagai metode ekstraksi yang berbeda, aktivitas antioksidan masih tergolong lemah. Secara spesifik, suatu senyawa dikatakan sebagai antioksidan sangat kuat jika nilai $\mathrm{IC}_{50}$ kurang dari $50 \mu \mathrm{g} / \mathrm{mL}$, kuat untuk $\mathrm{IC}_{50}$ bernilai $50-100 \mu \mathrm{g} / \mathrm{mL}$, sedang jika $\mathrm{IC}_{50}$ bernilai 100 $150 \mu \mathrm{g} / \mathrm{mL}$ dan lemah jika $\mathrm{IC}_{50}$ bernilai 151 $200 \mu \mathrm{g} / \mathrm{mL}[6]$.

\section{SIMPULAN}

Berdasarkan hasil penelitian yang telah dilakukan dapat disimpulkan bahwa perlakuan kulit blewah dengan metode maserasi ekstrak etanol memberikan aktivitas antioksidan lebih optimal dengan nilai $\mathrm{IC}_{50}(583,19 \mathrm{mg} / \mathrm{L})$ yang berbeda nyata $(\mathrm{P}<0,05)$ dengan perlakuan lain. Aktivitas antioksidan daging dan kulit buah blewah masih tergolong sangat lemah dan belum sebanding dengan larutan vitamin $\mathrm{C}$ dengan nilai aktivitas 290,33 mg/L.

\section{SARAN}

Pada daging dan kulit buah blewah terdapat senyawa lain yang berpotensi memberikan aktivitas antioksidan, oleh karena itu perlu dilakukannya penelitian lebih lanjut tentang senyawa sitrulin pada seluruh bagian blewah sehingga diharapkan dapat memberikan aktivitas antioksidan yang lebih baik. Selain itu, perlu juga dilakukan formulasi sediaan dari blewah sehingga dapat diketahui ekstrak blewah juga dapat memberikan aktivitas antioksidan pada tubuh.

\section{DAFTAR PUSTAKA}

[1]. USDA. United States Department of Agriculture, National Nutrient Database. 2011. Basic Report: 09181, Melons, cantaloupe, raw. USA: USDA.

[2]. Akashi, K., Miyake, C., dan Yakota, A. 2001. Citrulline, a Novel Compatible Solute in Drought-Tolerant Wild Watermelon Leaves, is an Efficient Hydroxyl Radical Scavenger. FEBS Letters 508: 438-442.

[3]. Curis, E., Nicolis,I., Moinard, C., Osowska,S.,Zerrouk, N., Benazeth, S., dan Cynober, L. 2005. Almost all about sitrulin in mammals. Amino Acids 29. 177-205.

[4]. Silabi, Nadia F. 2015. Uji Antioksidan Ekstrak Pigmen Karotenoid dan Sitrulin Pada Kulit Buah Blewah (Cucumis melo L.) Secara In Vitro (Metode DPPH) [skripsi]. Bogor: Sekolah Tinggi Teknologi Industri dan Farmasi Bogor. Hal : 42

[5]. Sroimori, T., Srisunton, S., dan Rawdkuen, S. 2011. Extraction of Phenolic Antioxidant From Peels and Seeds of the Royal Project's Fruits. Thai Journals of Agricultural Science 44(5): 113-117.

[6]. Supiyanti, W., Wulansari, E.D., dan Kusmita, L. 2010. Uji Aktivitas Antioksidan dan Penentuan Kandungan Antosianin Total Kulit Buah Manggis (Garcinia mangostana L), Majalah Obat Tradisional, 15(2): 64-70 